\title{
WindSat and RAMA Buoy: a comparison of ocean-atmosphere data
}

\author{
Ayu Agustin ${ }^{1}$, Wijaya Mardiansyah ${ }^{1}$, Dedi Setiabudidaya ${ }^{1}$ and Iskhaq Iskandar ${ }^{1,2, *}$ \\ ${ }^{1}$ Physics Department Faculty of Mathematics and Natural Sciences, Sriwijaya University, 30662 Inderalaya, Indonesia \\ ${ }^{2}$ Environmental Research Center, Sriwijaya University, 30139 Palembang, Indonesia
}

\begin{abstract}
Ocean-atmosphere data deployed along the equatorial Indian Ocean were used for validating the ocean-atmosphere data recorded by the WindSat satellite. Three RAMA Buoys mounted at $67^{\circ} \mathrm{E}, 80.5^{\circ} \mathrm{E}$ and $90^{\circ} \mathrm{E}$ along the equator were used to evaluate the sea surface temperature (SST), wind speeds and precipitation obtained by the WindSat satellite, except for precipitation in the eastern equatorial Indian Ocean. The SST from WindSat shows significant correlation with that from RAMA Buoy, with coefficient correlations of $0.95,0.88$ and 0.83 , respectively. The root mean square errors (RMSEs) of the WindSat SST relative to RAMA Buoy data were $0.28,0.29$ and $0.32{ }^{\circ} \mathrm{C}$, respectively. In this study, the quality performances of the WindSat wind speed were also satisfactory, with coefficient correlation of $0.64,0.7$ and 0.58 in each RAMA buoy. The corresponding RMSEs of the wind speeds were 1.46, 1.37 and $1.63 \mathrm{~ms}^{-1}$. Meanwhile, the WindSat precipitations reveal weak correlation with RAMA Buoy data, in particular in the eastern equatorial Indian Ocean. Overall, the WindSat satellite data for each measurement parameters can be used to replace in-situ observation data after taking into account the measurement errors.
\end{abstract}

\section{Introduction}

The Indian Ocean is the smallest of all oceans. It has a north-south extent of $9600 \mathrm{~km}$ from antartica to the inner Bay of Bengal and spans $7800 \mathrm{~km}$ in east-west direction between southern Africa and western Australia. Without its southern ocean part it covers an area of $48.10^{6} \mathrm{~km}^{2}$. If the southern ocean part is included, the area increases to $74.10^{6} \mathrm{~km}^{2}[1]$.

The Indian Ocean has unique characteristics and different from the ocean and atmospheric circulation in the Pacific Ocean and Atlantic Ocean. Wind circulation in the Indian Ocean is dominated by monsoon winds that change direction every six months [2]. Meanwhile, ocean circulation especially in the Indian Ocean around the equator characterized by the flow Wyrtki [3]. Flow Wyrtki a surface current that flows from west to east along the equatorial Indian Ocean. Wyrtki currents have an important role in distributing the mass of water and heat in the Indian Ocean.

So far, the data in-situ measurement result in the Indian Ocean is still very limited and far behind when compared with the other two ocean. One of the multinational cooperation program to perform in-situ measurement in the Indian Ocean is a Research moored Array for African-Asian-Australian Monsoon Analysis and Prediction (RAMA) buoy network. RAMA program is part of a multi-national coorperation activities for the in-situ measurements in the tropics known as the Tropical Atmosphere Ocean (TAO) project.
Measurement parameters include parameters dynamics of the atmosphere and ocean dynamics parameters.

\section{Data}

\subsection{WindSat satellite}

The WindSat Polarimetric Radiometer was developed by the Naval Research Laboratory (NRL) Remote Sensing Division and Naval Center for Space Technology for the U.S. Navy and the National Polar-orbiting Operational Environmental Stellite System (NPOESS) Integrated Program Office (IPO).

WindSat data product include the standard set of measurements (sea surface temperature, wind speed, water vapor, cloud liquid water, and rain rate) and differ from other RSS radiometer products in that we can include additional measurements:

- WDIR: Because of its polarimetric channels, WindSat can measure surface wind direction. WDIR is only provided if the wind speed exceeds $3 \mathrm{~m} / \mathrm{s}$ and the rain rate is below $15 \mathrm{~mm} / \mathrm{hr}$.

- WSPD_AW: We have made significant progressin improving the retrival of wind speeds in the presence of rain. We can retrieve WindSat surface wind speed in both rain-free and rainy atmospheres. We combine various algorithms, including a global wind speed through rain algorithm that works under all rain conditions and $\mathrm{H}$-wind algorithm that has been

\footnotetext{
*Corresponding author: iskhaq@mipa.unsri.ac.id
} 
specially trained for tropical cyclones. The final allweather wind speed, WSPD_AW, provided in our binary files is a smooth blend between the standard wind speed obtained in non-raining conditions WSPD_LF, the global wind speed through rain and the $\mathrm{H}$-wind derived wind speed.

Gridded data files are organized according to observation date. All date and time are Coordinated Universal Time (UTC), also known as Greenwich Mean Time (GMT), Zulu Time (Z), universal Time (UT), and World Time.

\subsection{RAMA Buoy}

The Tropical Moored Array Programs consist of three different TAO Buoy Arrays. They are TAO/TRITON in Pacific, Prediction and Research Moored Array (PIRATA) in Atlantic, and RAMA in the Indian Ocean. The Research Moored Array for African-AsianAustralian Monsoon Analysis and Prediction (RAMA ) Buoy network over the Indian Ocean, part of the Tropical Atmosphere Observation (TAO) program helps to fill this data void to good extend.

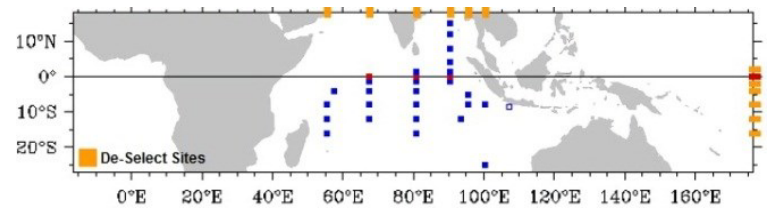

Fig. 1. Location of RAMA Buoy

The measurements on the RAMA surface floats include the meteorological parameters like air temperature, relative humidity, and wind velocity at height of 3-4 m above the mean sea level (MSL). Daily averages of all data and several hourly samples per day of most meteorological variables are transmitted to shore in real time via Service Argos [4]-[6]. Parameter and period of this study data contained in the Table 1 .

Table 1. WindSat satellite data and RAMA buoy data

\begin{tabular}{|c|c|}
\hline Parameters & Period \\
\hline \multirow{5}{*}{ Sea Surface Temperature } & $1 / 1 / 2015-31 / 12 / 2015$ \\
& $\left(0^{\circ} \mathrm{LU}, 67^{\circ} \mathrm{BT}\right)$ \\
& $9 / 7 / 2013-17 / 8 / 2014$ \\
& $\left(0^{\circ} \mathrm{LU}, 80.5^{\circ} \mathrm{BT}\right)$ \\
& $9 / 7 / 2013-31 / 12 / 2015$ \\
& $\left(0^{\circ} \mathrm{LU}, 90^{\circ} \mathrm{BT}\right)$ \\
\hline & $1 / 1 / 2015-31 / 12 / 15$ \\
& $\left(0^{\circ} \mathrm{LU}, 67^{\circ} \mathrm{BT}\right)$ \\
& $9 / 7 / 2013-16 / 8 / 2014$ \\
& $\left(0^{\circ} \mathrm{LU}, 80.5^{\circ} \mathrm{BT}\right)$ \\
& $17 / 5 / 2013-30 / 8 / 2015$ \\
& $\left(0^{\circ} \mathrm{LU}, 90^{\circ} \mathrm{BT}\right)$ \\
\hline & $1 / 1 / 2015-31 / 12 / 15$ \\
& $\left(0^{\circ} \mathrm{LU}, 67^{\circ} \mathrm{BT}\right)$ \\
& $31 / 10 / 2012-31 / 12 / 15$ \\
& $\left(0^{\circ} \mathrm{LU}, 80.5^{\circ} \mathrm{BT}\right)$ \\
& $21 / 5 / 2006-18 / 2 / 2009$ \\
& $\left(0^{\circ} \mathrm{LU}, 90^{\circ} \mathrm{BT}\right)$ \\
\hline
\end{tabular}

In this study using data from 2015 due to the data of the three parameters in 2015 are of better quality than in other years.

Measurement data be seen in the graph below (a)

(b)

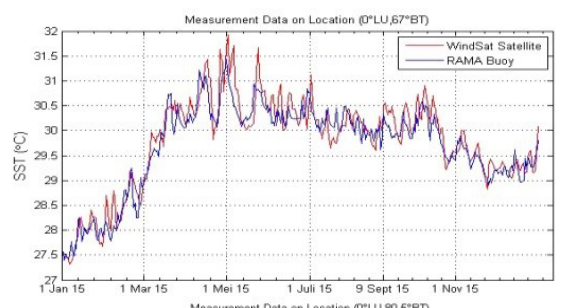

(c)
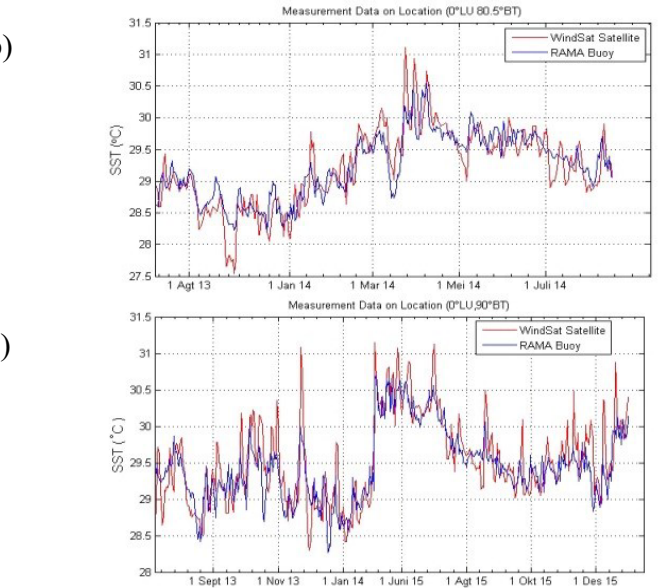

Fig. 2. The Graph comparison of sea surface temperature WindSat satellite and RAMA Buoy on location (a) $0^{\circ} \mathrm{LU}, 67^{\circ} \mathrm{BT}(\mathrm{b}) 0^{\circ} \mathrm{LU}, 80.5^{\circ} \mathrm{BT}$ and (c) $0^{\circ} \mathrm{LU}, 90^{\circ} \mathrm{BT}$

(a)

(b)

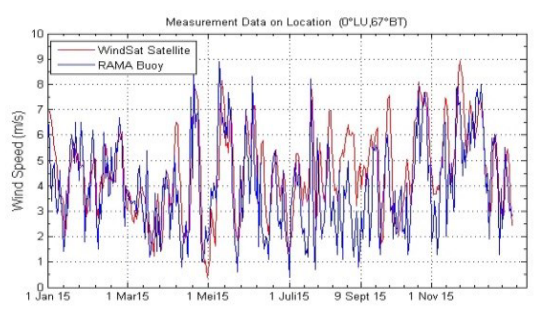

(c)
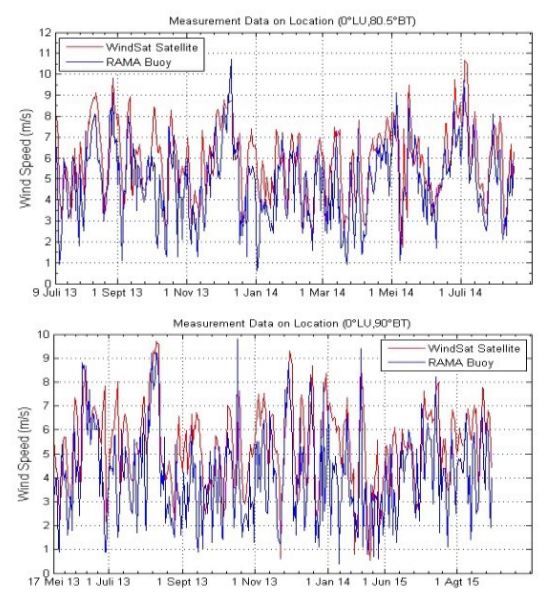

Fig. 3. The Graph comparison of wind speed WindSat satellite and RAMA Buoy on location (a) $0^{\circ} \mathrm{LU}, 67^{\circ} \mathrm{BT}$ (b) $0^{\circ} \mathrm{LU}, 80.5^{\circ} \mathrm{BT}$ and (c) $0^{\circ} \mathrm{LU}, 90^{\circ} \mathrm{BT}$ 
(a)

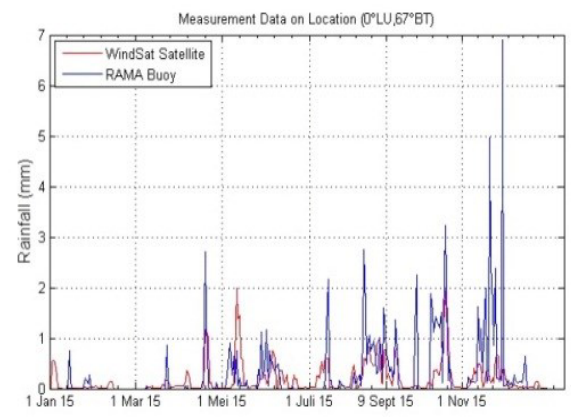

(b)

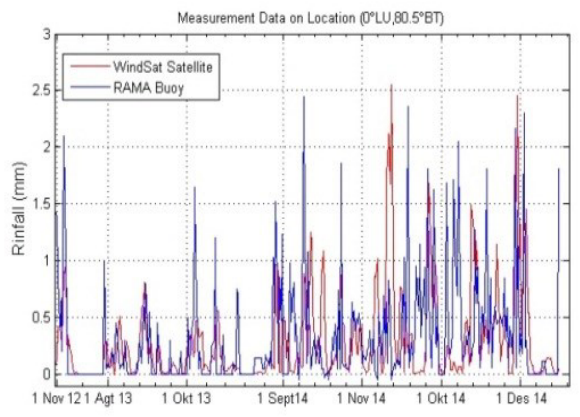

(c)

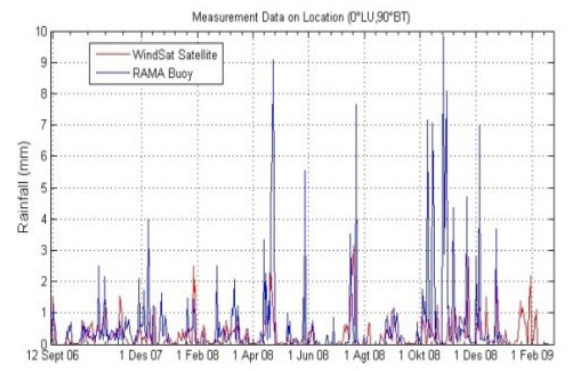

Fig. 4. The Graph comparison of rainfall WindSat satellite and RAMA Buoy on location (a) $0^{\circ} \mathrm{LU}, 67^{\circ} \mathrm{BT}$ (b) $0^{\circ} \mathrm{LU}, 80.5^{\circ} \mathrm{BT}$ and (c) $0^{\circ} \mathrm{LU}, 90^{\circ} \mathrm{BT}$

\section{Methodology}

WindSat satellite data downloaded from Asia-Pacific Data-Research-Center (APDRC). This data has a daily temporal resolution and a spatial resolution of $0.25^{\circ} \mathrm{x}$ $0.25^{\circ}$ and the RAMA Buoy data downloaded from Tropical Atmosphere Ocean (TAO) project. As for the in-situ measurement data that will serve as reference data is the measurement RAMA Buoy data at three location along the equatorial Indian Ocean, each at $0^{\circ} \mathrm{LU}, 67^{\circ} \mathrm{BT}$; $0^{\circ} \mathrm{LU}, 80.5^{\circ} \mathrm{BT}$ and $0^{\circ} \mathrm{LU}, 90^{\circ} \mathrm{BT}$. This study will calculate the level of accuracy WindSat satellite measurement by comparing them with the data in-situ measurement from RAMA Buoy. Sea surface temperature, rainfall and wind speed parameters were used in this study.

Sea Surface Temperature (SST) is a measure of energy caused by the movement of molecules on the surface of the sea. SST measurement can be made directly using a measuring instrument which generally is Conductivity Temperature Depth (CTD). If the term of the dynamics of the atmosphere, the water of the Indian Ocean has the unique and complex nature. This condition causes Asian-Australian Monsoon and Indian-
African Monsoon. This will cause the circulation of currents especially sufficient surface complex [3],[7]. Wind over the Indian Ocean is dominated by annual circulation pattern (seasonal). Wind circulstion pattern in the semiannual period is a characteristic of wind circulation in the equatorial Indian Ocean which distinguishes it from the other two oceans, Pacific Ocean and Atlantic Ocean [8]. Equatorial rainfall pattern has the characteristic two peaks of rainfall on an annual cycle [9].

This research were used statistical analysis and analysis of standard errors to calculate the level of accuracy satellite measurement.

\subsection{Linier correlation}

The correlation is a way of determining how well two (or more) variables co-vary in time or space. For two random variables. The correlation coefficient can be written:

$$
r_{x y}=\frac{1}{N-1} \sum_{i=1}^{N} \frac{(x i-\bar{x})-(y i-\bar{y})}{s_{x} s_{y}}
$$

Where $s_{x}$ and $s_{y}$ are the standart deviations for the two data record. For $r= \pm 1$, the data points (x,y) cluster along a straight line and the sampels are said to have a perfect correlation (+) for "in-phase" fluctuations and minus (-) for $180^{\circ}$ 'out-of-phase"fluctuations). For $r \approx 0$, the points are scattered randomly on the graph and there is little or no relationship between the variables [10].

\subsection{Linier regression}

Linier regression analysis was used to determine the shape of the relationship between variables. Intended use this analysis is to estimate the value of a avariable in relation to the other variables that are known through the regression line equation [11]. The general form of linier regression is:

$$
y=a+b x
$$

where a are intercept and $b$ are slope or gradient of the line. $\mathrm{y}$ is a dependent variable and $\mathrm{x}$ is a independent variable. The constants $\mathrm{a}$ and $\mathrm{b}$ are calculated used equation :

$$
\begin{gathered}
a=\frac{\left(\sum y \sum x^{2}\right)-\left(\sum x \sum x y\right)}{N\left(\sum x^{2}\right)\left(\sum x\right)^{2}} \\
a=\left(\frac{\sum y}{N}\right)-b\left(\frac{\sum x}{N}\right) \\
b=\frac{N\left(\sum x y\right)-\left(\sum x \sum y\right)}{N\left(\sum x^{2}\right)\left(\sum x\right)^{2}}
\end{gathered}
$$




\subsection{Analysis standart errors}

\subsubsection{Mean bias error (MBE)}

MBE value indicated systematic error estimation data (satellite). If a positive value means the estimation data is greater than the measurement data. This means that the data was biased low, if a negative value meansthe data estimation less of the measurement data.

$$
M B E=\frac{1}{N} \sum_{i=1}^{N}(x i-y i)
$$

\subsubsection{Root mean square error (RMSE)}

RMSE is used to indicate random error of the measurement, which in this research is data from satellite.

$$
R M S E=\sqrt{\left(\frac{1}{N} \sum_{i=1}^{N}\{x i-(M B E)-y i\}^{2}\right)}
$$

\subsubsection{Mean absolute error (MAE)}

MAE is used to measure the accuracy of estimate with the average error in unit of the same size as the original.

$$
M A E=\frac{1}{N} \sum_{i=1}^{N}|x i-y i|
$$

Where $\mathrm{xi}$ is the estimated value (satellite data), yi is the value of in-situ measurement (RAMA Buoy), and $\mathrm{N}$ is the number of data used.

\section{Result and discussion}

\subsection{Sea surface temperature}

The result of calculation using the equation 1,6,7 and 8 show in Table 2.

Table 2. The correlation coefficient and error of sea suface temperature

\begin{tabular}{|c|c|c|c|}
\hline Parameter & $\mathbf{0}^{\circ} \mathbf{L U , 6 7}{ }^{\circ} \mathbf{B T}$ & $\mathbf{0}^{\circ} \mathbf{L U , 8 0 . 5}{ }^{\circ} \mathbf{B T}$ & $\mathbf{0}^{\circ} \mathbf{L U , 9 0}{ }^{\circ} \mathbf{B T}$ \\
\hline r & 0.95 & 0.88 & 0.83 \\
\hline MBE & 0.09 & -0.02 & 0.07 \\
\hline MMSE & 0.28 & 0.29 & 0.32 \\
\hline
\end{tabular}

The results of Figure 2 measuring in all of located showed sea surface temperature data obtained from WindSat satellite that have high value than results measuring of RAMA buoys. That caused sea surface temperature was recorded by WindSat satellite is temperature in layers of sea surface, meanwhile sea surface temperature in-situ is sea surface temperature in deepth 1-2 $\mathrm{m}$ in below surface of the sea. As known that sea surface temperature was influenced by meteorology conditions, like as rainfall and velocity of wind that have high variations. This allegedly cause temperature was recorded by RAMA bouys that also have high variation.

(a)

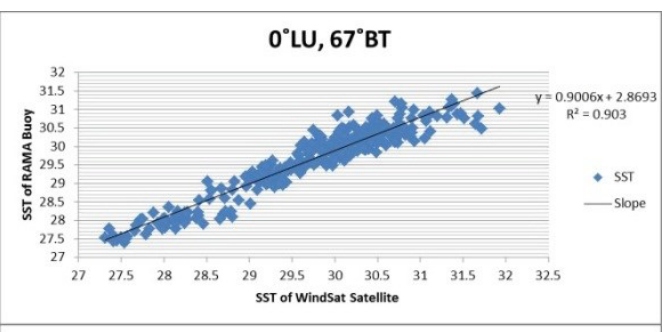

(b)

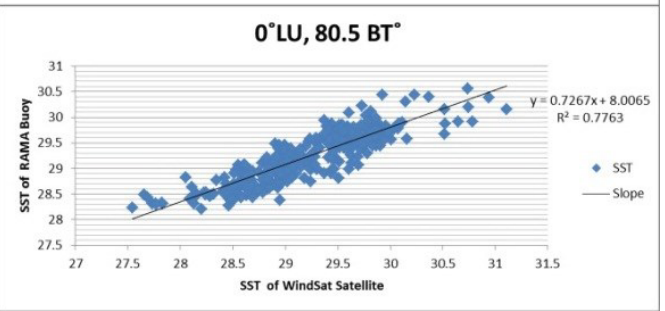

(c)

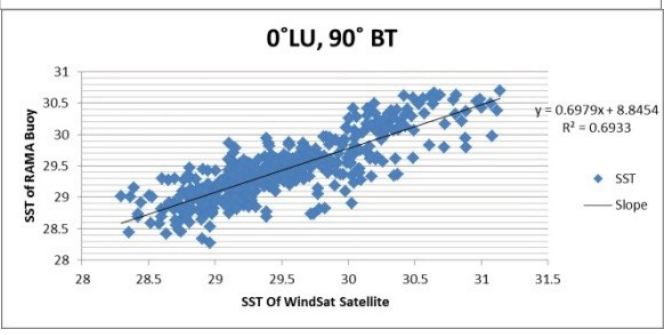

Fig. 5. The Graph linier regression of sea surface temperature (a) $0^{\circ} \mathrm{LU}, 67^{\circ} \mathrm{BT}$ (b) $0^{\circ} \mathrm{LU}, 80.5^{\circ} \mathrm{BT}$ and (c) $0^{\circ} \mathrm{LU}, 90^{\circ} \mathrm{BT}$

The highest correlation coefficient was shown on location $0^{\circ} \mathrm{LU}, 67^{\circ} \mathrm{BT}$ i.e $\mathrm{r}=0.95$. The correlation coefficient $r \approx 1$, the points are scattered regularly on the graph (show in figure 5) and there is perfect relationship between the variables.

The correlation coefficient obtained due to the values of systematic error is small. This is reinforced by the result of the linier regression.

\subsection{WindSpeed}

The result of calculation using the equation $1,6,7$ and 8 show in Table 3.

Table 3. The correlation coefficient and error of wind speed

\begin{tabular}{|c|c|c|c|}
\hline Parameter & $\mathbf{0}^{\circ} \mathbf{L U , 6 7}{ }^{\circ} \mathbf{B T}$ & $\mathbf{0}^{\circ} \mathbf{L U , 8 0 . 5}{ }^{\circ} \mathbf{B T}$ & $\mathbf{0}^{\circ} \mathbf{L U , 9 0}{ }^{\circ} \mathbf{B T}$ \\
\hline $\mathrm{r}$ & 0.64 & 0.7 & 0.58 \\
\hline $\mathrm{MBE}$ & 0.59 & 0.98 & 1.24 \\
\hline $\mathrm{RMSE}$ & 1.46 & 1.37 & 1.63 \\
\hline $\mathrm{MAE}$ & 1.23 & 1.34 & 1.64 \\
\hline
\end{tabular}

The results of measuring WindSat satellite couldn't caught signal with short time variation. That is showed in Fig.3, where the result of the graph measuring WindSat satellite more smooth than the result of RAMA 
Buoys measuring. As known WindSat satellite caught signal in high variation. This allegedly cause wind speed was recorded by RAMA Buoys that also have high variation.

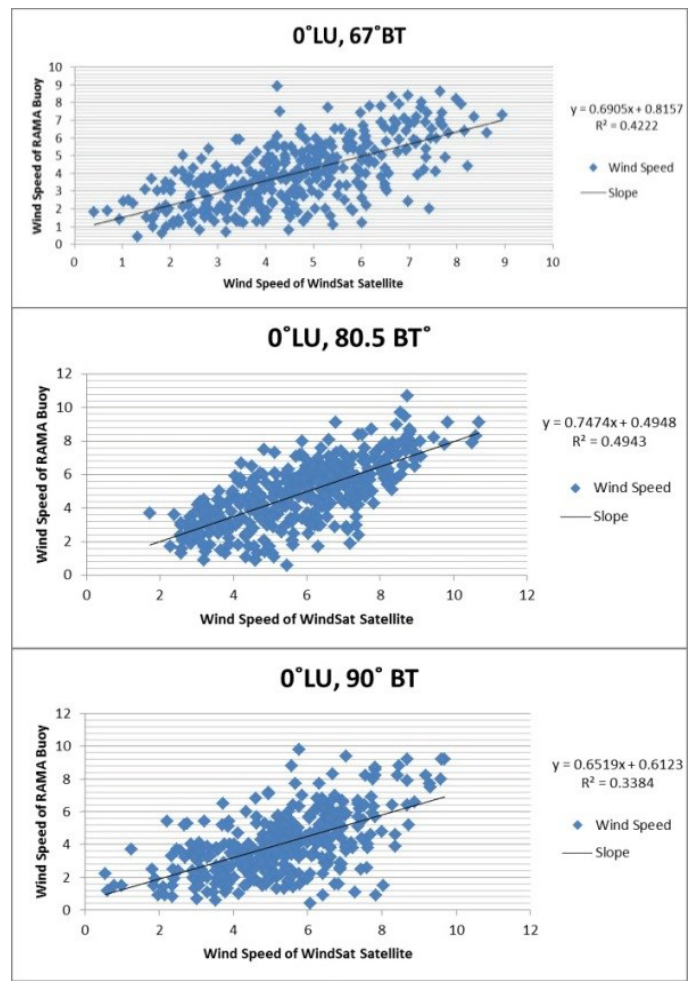

Fig. 6. The Graph linier regression of wind speed (a) $0^{\circ} \mathrm{LU}, 67^{\circ} \mathrm{BT}$ (b) $0^{\circ} \mathrm{LU}, 80.5^{\circ} \mathrm{BT}$ and (c) $00^{\circ} \mathrm{LU}, 90^{\circ} \mathrm{BT}$

\subsection{Rainfall}

The highest correlation coefficient was shown on location $0^{\circ} \mathrm{LU}, 80.5^{\circ} \mathrm{BT}$ i.e $\mathrm{r}=0.7$. The correlation coefficient the points are scattered regularly on the graph (show in figure 6) and there is good relationship between the variables.

The result of calculation using the equation $1,6,7$ and 8 show in Table 4.

Table 4. The correlation coefficient and error of wind speed

\begin{tabular}{|c|c|c|c|}
\hline Parameter & $0^{\circ} \mathrm{LU}, 67^{\circ} \mathrm{BT}$ & $0^{\circ} \mathrm{LU}, 80.5^{\circ} \mathrm{BT}$ & $0^{\circ} \mathrm{LU}, 90^{\circ} \mathrm{BT}$ \\
\hline $\mathrm{r}$ & 0.41 & 0.27 & 0.2 \\
\hline $\mathrm{MBE}$ & -0.10 & -0.02 & -0.15 \\
\hline $\mathrm{RMSE}$ & 0.61 & 0.52 & 1.18 \\
\hline $\mathrm{MAE}$ & 0.25 & 0.31 & 0.04 \\
\hline
\end{tabular}

The correlation coefficient was shown the points are scattered randomly on the graph (show in figure 7) and there is no relationship between the variables.

The results of statistic test of rainfall measure showed correlation value between WindSat satellite data and RAMA bouys data have small coefficien correlation and high errors. That caused spacial resolution data of WindSat satellite $(0.25 \times 0.25)$ couldn't caught signal detail in smaller location than resolution. (a)

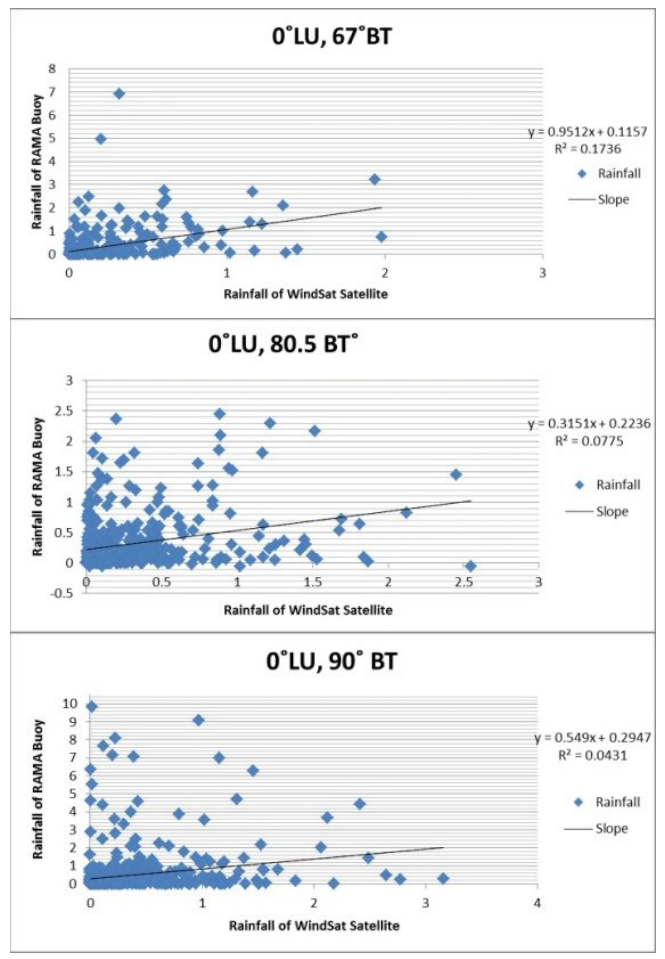

Fig. 7. The Graph linier regression of rainfall (a) $0^{\circ} \mathrm{LU}, 67^{\circ} \mathrm{BT}$ (b) $0^{\circ} \mathrm{LU}, 80.5^{\circ} \mathrm{BT}$ and (c) $0^{\circ} \mathrm{LU}, 90^{\circ} \mathrm{BT}$

The main obstacle to search information atmosphere-Ocean data (sea surface temparature, wind speed, and rainfall) from radiometric measure is correction atmosphere. Cloud made some problem to measure. Because make sea surface randomly. Part of satellite data was contaminate by effect of cloud that must be identification and elimination from processing procedure.

\section{Conclusion}

The greater the systematic errors in measurement data, the smaller the correlation coefficient resulting in less efficient estimation data (satellite) to replace the in-situ data. This is reinforced by the result of the linier regression on every measurement parameter used in this research.

Authors are grateful to the Physics Department, Faculty of Mathematics and Natural Sciences and Environmental Research Center, Sriwijaya University for the encouragement.

\section{References}

1. M. Tomzack, and J.S. Godfrey, Regional Oceanography: an Introduction (2011)

2. F.A. Schott, P. Julian, Jr. McCreary, The Monsoon Circulation of the Indian Ocean, Progress in Oceanography, 51, 1-123 (2001)

3. K.Wyrtki, An Equatorial Jet in the Indian Ocean, Science, 181, 264-264 (1973)

4. S.I. Rani, and M.D Gupta, 
5. Oceansat-2 and RAMA Buoy Wind : A Comparison, 122 (J.Earth Syst.Sci, 2013)

6. S.C.M. Prakash, R.M. Gariola, S. Pokhrel, Surface Freshwater Flux Estimation Using TRMM Measurements over the Tropical Oceans, 1, 225-234 (Atmospheric and Climate Science, 2011)

7. M.J. McPhaden, G. Meyes, K.. Ando, Y. Maumoto, V.S.N. Murty, M., Syamsudin F. Ravichandran, J. Vialard, L. Yu and W. Yu, RAMA the Research Moored Array for African-Asian-Australian Monson Analysis and Prediction, 90, 459-480 (Bull.Am. Meteor.Soc, 2009)
8. Martono, Karakteristik dan Variabilitas Bulanan Angin Permukaan di Perairan Samudera Hindia (2009)

9. I. Iskandar, Diktat Matakuliah Hidrodinamika Atmosfer dan Laut ( 2015)

10. Bannu, D.A. Suriamiharja, N. Takeuchi., H. Kuze, Impact of the ENSO and IOD Phenomena : LongTerm Analysis in Indonesian Region, 3-7 (36 ${ }^{\text {th }}$ COSPAR Scientific Assembly, 2003)

11. W.J. Emery, R.E. Thomson, Data Analysis Metods in Physical, 233-238 (Elsevier, 2004)

12. Spiegel, R. Murray, Theory and Problems of Statistics, Schaum's Outline Series: McGraw-Hill, 311-313 